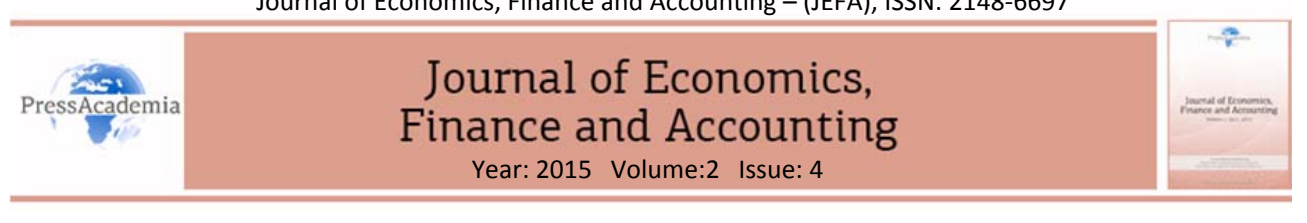

\title{
THE MEASUREMENT OF INTELLECTUAL CAPITAL AND THE EFFECTS ON FIRM VALUE: AN APPLICATION IN CEMENT INDUSTRY
}

\section{DOI: 10.17261/Pressacademia.2015414366}

\author{
Selcuk Kendirli', Zuhal Akgun², Nigar Ozcetin ${ }^{3}$ \\ ${ }^{1} H$ itit University. selcukkendirli@hitit.edu.tr \\ ${ }^{2}$ Bozok University. zuhal.akgun@bozok.edu.tr \\ ${ }^{3}$ Bozok University. nigar.ozcetin@bozok.edu.tr
}

\section{Keywords}

Intellectual capital, market value, net assets ratio

JEL Classification

E22, E24, O34

\section{ABSTRACT}

Improvement in knowledge and technology increase the importance of Intangible Assets or Intellectual Capital for today's companies. Intellectual capital or intangible assets played a huge important role over being sold of the companies at a very high price of their market values. In this study, at first, the definition of intellectual capital or intangible assets is made; also its measuring techniques are explained. And then the Intellectual Capital of 5 companies, which are operating in cement industry in Marmara Region, are tried to calculate by "Calculated The Method of Intangible Assets". In this study we studied with 5 firms which ones operating in the Marmara region and listed in Istanbul Stock Exchange (BIST). We used their data between 20102011, 2011-2012 and 2012-2013 which are explained by their financial statements. We took their financial statements from The Public Disclosure Platform (KAP). First, we calculated to firms' profit before interest and taxes by using their data. After that we calculated to average intellectual capital value with using to tangible assets data.

\section{ENTELEKTÜEL SERMAYENIN ÖLLCÜLMESI VE FIRMA DEĞERINE ETKILERi: ÇIMENTO SEKTÖRÜNDE BIR UYGULAMA}

Anahtar Kelimeler

Yatırım, nakit akışları, finansal kısıtlar, işletme grupları, Türkiye

JEL Sınıflandırması E22, E24, O34

\section{ÖZET}

Bilgi ve teknoloji alanındaki gelişmeler, Maddi Olmayan Varlıklar olarak da adlandırabileceğimiz Entelektüel Sermayenin, günümüz işletmeleri için önemini arttırmış̧ır. İ̧̧letmelerin sahip olduğu maddi olmayan varlıklarının ya da entelektüel sermayesinin varlı̆̆ı işletmelerin piyasa değerinin çok üzerinde satılmasında büyük rol oynamaktadır. Bu çalışmada, ilk olarak Entelektüel Sermaye tanımına değinilmiş, ölçüm yöntemleri anlatılmış ve son olarak "Hesaplanmış Maddi Olmayan Değer Yöntemi" kullanılarak Marmara bölgesinde bulunan, çimento sektöründe faaliyet gösteren 5 firmanın finansal tabloları incelenerek entelektüel sermayeleri hesaplanmaya çalışılmıştır. Bu çalışmada Marmara Bölgesinde faaliyet gösteren ve Borsa İstanbul'da (BIST) kote olmuş 5 firma verileri üzerinde çalışılmıştır. Gerekli veriler bu firmaların açıklamış oldukları 2010-2011, 2011-2012 ve 2012-2013 yıllarına ait mali tablolarından alınmıştır. Bu mali tablolar Kamuyu Aydınlatma Platformundan (KAP) alınmıştır. Elde edilen verilerden faydalanılarak önce işletmenin faiz ve vergi öncesi karı hesaplanmıştır. Bu veriler kullanılarak ortalama maddi varlıklarla birlikte yaklaşık entellektüel sermaye değerleri hesaplanmıştır. 


\section{GíRiş}

Küreselleşme sürecinin baş döndürücü hızla ilerlemesi ve bilgi çağına geçiş ile birlikte, bilgi her kesim için vazgeçilmez bir unsur haline gelmiştir. Bilgiye ulaşmanın ve bilgiyi yönetebilmenin giderek önem kazanması da işletmeler için maddi varlıkların yanında maddi olmayan varlıklarının işletmenin değerinin ölçülmesinde etkin bir faktör olduğunu ortaya çıkarmıştır. Bunun farkına varan günümüz işletme yöneticileri maddi varlıkları kadar maddi olmayan varlıklarına da önem vermeye başlamışlardır. Entelektüel Sermaye, rekabet avantajı sağlamak ve işletmelerin piyasa değerinin artmasında çok büyük katkılar sağlamaktadır.

$\mathrm{Bu}$ çalışmada entelektüel sermayenin unsurları literatürdeki çalışmalar ışığında tanımlanmaya çalışı Imış, temel ölçme ve değerleme yöntemlerinden bazıları incelenmiştir. Çalışmanın amacı çimento sektöründe faaliyet gösteren halka açık şirketlerin "Hesaplanmış Maddi Olmayan Değer Yöntemi" kullanılarak Entellektüel Sermayelerini hesaplamak ve defter değeri ile net aktif oran içindeki yerini bulabilmektir. Bu amaçla Kamu Aydınlatma Platformu resmi internet sitesinde (kap.gov.tr) yer alan çimento şirketlerinin 2011-2012-2013 yıllarına ait finansal tabloları incelenmiş, Entelektüel Sermayeleri “Hesaplanmış Maddi Olmayan Değer Yöntemi” kullanılarak hesaplanmıştır.

Çalışmada işletmenin mali tablolarından elde edilen veriler kullanılarak öncelikle seçilen firmaların belirlenen dönemler için ortalama vergi öncesi karları hesaplanmış ve ortalama varlık değerine oranlanmıştır. Sonraki aşamada sektörel açıdan işletmenin getiri fazlası hesaplanarak olası vergi hesaplaması hesaplanmış ve maddi olmayan varlıkların primi olarak ifade edilebilecek kısım hesaplanmıştır. Hesaplanan prim değerinin net bugünkü değeri hesaplanarak varsayılan ağırlıklı sermaye maliyeti oranına bölerek firmanın yaklaşık entelektüel sermaye tutarı hesaplanmış ve defter değeri ile farkları karşılaştırılmıştır. Firmaların piyasa performanslarının da görülebilmesi açısından entelektüel sermayeler ile piyasa performansları da karşılaştırılmıştır.

\section{ENTELLEKTÜEL SERMAYENIN TANIMI}

1980 'li yıllar ve sonrasında bilgi ekonomisi olarak ifade edilen yeni bir ekonomik yapının meydana gelmesi işletmeler açısından maddi olmayan varlıkların öneminin artmasına neden olmuştur.(Ercan vd., 2003:96). İşletmeler bu varlıkların kritik önemini fark etmişler ve dikkatlerini maddi varlıkların yönetiminden maddi olmayan varlıkların yönetimine kaydırmışlardır (Önce, 1999: 12). Bunun sonucunda işletmeler maddi varlık değerlerinin çok üzerindeki değerlerle piyasada elde değiştirmeye başlamıştır. Bu da defter değeri ile piyasa değeri arasındaki farkın artmasına neden olmuş ve entelektüel sermaye olarak adlandırılmıştır. (Özçetin, 2010:5) Entelektüel sermayenin çeşitli tanımları yapılmıştır.

Stewart tarafından 1991 yılında yapılan tanım şöyledir; "işletmeye pazarda rekabet avantajı sağlayan, çalışanların bildiği her şey" olarak tanımlamıştır (Görmüş, 2009: 59). Edvinsson ve Sullivan, entelektüel sermayeyi "bilginin değere dönüştürülmesi" biçiminde tanımlamıştır (İpçioğlu, 2007:134). Maddi olmayan varlık veya entelektüel sermaye, insan kaynakları, know-how, entelektüel mülkiyet hakları, imalat işlemleri, organizasyonel yapı, problem çözme kapasitesi ve iç ve dış ilişkiler gibi varlıklardan oluşur (Özçetin, 2010: 9). 
“Entelektüel sermaye, zenginlik yaratmak üzere kullanıma sokulabilen entelektüel varlıklardır; yani bilgi, entelektüel mülkiyet ve deneyim" olarak tanımlanabilir. Entelektüel sermayenin bazı özellikleri aşağıda yer almaktadır (Cengiz ve Zor 2013:41):

1. Entelektüel sermaye, işletme bilançosundan tam olarak elde edilemeyen maddi olmayan varlıkların toplamıdır.

2. Entelektüel sermaye, işletmelerin rekabet üstünlüğünün kalıcılığının sağlanmasının temel kaynağıdır.

3. İşletmenin entelektüel sermayesinin yönetimi önemli bir yönetsel sorumluluktur.

4. Entelektüel sermayedeki artış veya azalışların, entelektüel performans olarak adlandırılması mümkündür; ölçülebilir ve görünür hale getirilebilmektedir.

5. Entelektüel sermayeyi ölçmek ve görünür hale getirmek için sistematik bir yaklaşım, işletmelerin türüne, büyüklüğüne, yapısına, sahiplerine ve coğrafi yerleşimine bağlı olmaksızın artan bir şekilde değerli hale gelmektedir.

\section{ENTELLEKTÜEL SERMAYE UNSURLARI}

\subsection{Insan Sermayesi}

İnsan sermayesi, çalışanların sahip olduğu örgütün bireysel bilgi stoğunu temsil eder ve insan sermayesinin özü organizasyon üyelerinin saf beynidir (Bontis vd., 2000:87). İnsan sermayesi, çalışanların işletmeyi terk ettiğinde kendileri ile beraber götürdükleri bilgi olarak tanımlanmaktadır (İpçioğlu, 2007:136). Hubert Saint-Onge, insan sermayesini müşterilere çözümler üretmek için çalışanların ihtiyaç duyduğu yetenekler olarak tanımlamaktadır (Karacan, 2005:186). İnsan sermayesinin geliştirilmesi çalışanlara eğitimler sağlanarak, çalışanların iş tatmin düzeyleri arttırılarak ve çalışanların motive edilmesi ile geliştirebilir (Alagöz ve Özpeynirci, 2007: 171).

Insan sermayesinin bileşenleri know-how, eğitim, meslek ile ilgili takdir edilen değerler, mesleki yeterlilik, girişimcilik coşkusu, değişime ayak uydurma, çalışanların yetenekleri olarak gösterilebilir (Çelik ve Perçin, 2000: 113).

\subsection{Yapısal Sermaye}

İşletme çalışanlarının verimliliğini destekleyen donanım, yazılım, veri tabanları, organizasyonel yapı, patentler, markalar ve diğer benzer şeylere yapısal sermaye denir (Şamiloğlu, 2002: 89). Yapısal sermaye kısaca eve gitmeyen bilgi olarak tarif edilebilir (Arıkboğa, 2003: 93).

Yapısal sermayenin bileşenleri patentler, ticari amblemler, tasarım hakları, ticari sırlar, telif hakları, hizmet ile ilgili amblemler, yönetim felsefesi, yönetim süreçleri, örgüt kültürü, finansal ilişkiler, bilgi sistemleri, ağ sistemleri olarak gösterilebilir (Çelik ve Perçin, 2000:113). 


\subsection{Müşteri Sermayesi}

Firmanın müşteri, satıcı ve tedarikçileri ile teması sonucu ortaya çıkan bilgiler olarak tanımlanabilir ( Uzay ve Savaş, 2003: 166).Müşteri sermayesinin bileşenleri markalar, müşteriler, müşteri bağlılığı, işletme adı, dağıtım kanalları iş ile ilgili iş birliği, lisans anlaşmaları, franchising anlaşmaları olarak gösterilebilir( Çelik ve Perçin, 2000: 13).

\section{ENTELLEKTÜEL SERMAYENIN ÖLÇÜLMESi}

Entelektüel sermayenin ölçülmesinde 3 yöntem kullanılmaktadır.

\subsection{Piyasa Değeri Oranı -Defter Değeri Oranı Yöntemi}

Bu yöntemde işletmenin piyasa değeri ile defter değeri arasındaki fark entelektüel sermaye olarak ölçülmektedir (Şişman, 2004: 3).

İşletmenin piyasa değeri, belli bir tarihte işletmenin sahip olduğu hisse senetlerine yatırımcılar tarafından ödemeye razı oldukları tutarı ifade eder. Defter değeri ise, işletmenin bilançosunda yer alan varlıklardan borçların düşülmesi sonucu elde edilmekte olan değeri ifade eder (Çıkrıkçı ve Daştan, 2002: 24).

Bu yöntemde bir firmanın entelektüel sermayesi, tutar olarak aşağıdaki formülle ifade edilir.

\section{ES= Piyasa Değeri - Defter Değeri}

Entelektüel sermayenin oran olarak ifade edilmesi ise aşağıdaki formülle hesaplanır

\section{ES= Piyasa Değeri / Defter Değeri}

Oran olarak hesaplanan ES'den, gerek firmanın geçmiş yıl verileri gerekse sektör ortalamaları ile karşılaştırmak suretiyle, daha anlamlı bilgiler elde edilebilmektedir (Uzay ve Savaş, 2003: 167).

\subsection{Tobin'in Q Oranı}

İsmini Nobel ödüllü iktisatçı James Tobin'den alan bu yöntem bir varlığın piyasa değeri ile bu varlığın yerine koyma maliyetinin karşılaştırılmasına dayanmakta, yöntemde varlığın piyasa değerinin, yerine koyma maliyetini aşan kısmı entelektüel sermaye olarak kabul edilmektedir (Uzay ve Savaş, 2003: 167).

Tobin Q Oranı şu formülle ifade edilmektedir:

\section{ES= Piyasa Değeri /Varlığın Yerine Koyma Maliyeti}

Tobin Q Oranı'nın birden büyük olması, işletmenin maddi olmayan varlıklarının yani entelektüel varlıklarının yüksek düzeyde olduğunu göstermektedir. Tobin $Q$ Oranı eğer 1 'den küçük ise işletmenin varlıklarının yerine koyma maliyetinin varlıkların getiri düzeyi tarafından karşılanamadığını göstermektedir (Daştan ve Çıkrıkçı, 2002: 25). 


\subsection{Hesaplanmış Maddi Olmayan Değer Yöntemi}

Bu yöntem işletmenin maddi olmayan varlıklarının veya entelektüel sermayesinin gerçeğe uygun değerlerinin hesaplanmasına yardım etmektedir (Çelik ve Perçin, 2000: 116).

Bu yöntemde izlenmesi gereken aşamalar şunlardır (Yalama, 2006: 35):

1. Aşama: Üç yıl için ortalama vergi öncesi kar hesaplanır.

2. Aşama Dönem sonu bilançosuna bakılarak ortalama maddi varlık değerleri alınır ve üç yılın ortalaması hesaplanır.

3. Aşama: Maddi varlıkların getirisi, kar ortalaması maddi varlıkların ortalama değerine bölünerek bulunur.

4. Aşama: Söz konusu üç yıl için sektörün maddi varlıklarının getiri oranı hesaplanır.

5. Aşama: Getiri fazlası hesaplanır. Sektörün ortalama getiri oranı işletmenin ortalama maddi varlıklarıyla çarpılır. Çıkan sonuç işletmenin maddi varlıklardan kazandığı tutarı gösterir. Bulunan rakam işletmenin 1. aşamada bulunan vergi öncesi kardan çıkarılır.

6. Aşama: Üç yıllık ortalama gelir vergisi hesaplanır ve bu ek getiriyle çarpılır. Vergi sonrası geliri bulabilmek için çıkan sonuç ek getiriden çıkarılır. Bu rakam maddi olmayan varlıklara atfedilecek primdir.

7. Aşama: Primin net bugünkü değeri hesaplanır. Bunun için primi işletmenin sermaye maliyeti gibi uygun bir orana bölmek gerekir.

\section{ENTELLEKTÜEL SERMAYE İLE FIRMA DEĞERi ARASINDAKi íLiŞKi}

Firmaların asıl hedefi, firma değerini maksimum yapmaktır. Bu hedefe ulaşan firmalar, çalışanlarına daha yüksek ücret ödeyerek daha garantili bir iş imkânı sağlayabilmekte, devlete daha fazla vergi ödeyebilmekte, finans kurumlarına olan borçlarını daha düzenli olarak takip etmekte ve ortaklar açısından, gerek temettü gerekse sermaye kazancı şeklinde daha fazla getiri sunabilmektedir (Zor ve Cengiz, 2013: 41).

Bir firmanın değeri sadece maddi duran varlıkların değerinden oluşmaz. Maddi duran varlıklar yanında, maddi olmayan duran varlıların da firma değerlemesinde değer yaratıcı unsurlar arasındadır. İşte bu nedenle, geçmişin entelektüel birikimi olan bilgi ile işletmecilik anlayışında sahip olunan sermayenin birleşiminden doğan ve işletmelerde entelektüel olarak ifade edilen maddi olmayan varlıklara sahip olma, onları kullanma ve yönetme firmalar için artı değer yaratmaktadır. Böylelikle, bir firmanın değeri genellikle fiziksel varlıkların değerinden daha büyük olmakta olup, bu durum defter değeri ile piyasa değerinin farklılaşması ile açıklanmaktadır (Öztürk ve Ünsal, 2003: 4)

Maddi olmayan varlıkların mobilitesinin, maddi varlıklara oranla yüksek olması bu varlıkların önemini artıran bir unsur olmuş, şirketlerin piyasa değerinin belirlenmesinde maddi olmayan varlıkların paylarında meydana gelen artış, son dönemlerde üzerinde çok durulan bir konu olmuştur. Dünyada finansın duyarlı kitlesini oluşturan topluluklar son dönemlerde hisse senedi fiyatlarıyla entelektüel sermaye arasındaki ilişkiyi tanımlamaya çalışmaktadır. Hisse senedi piyasalarında bir bilgi şirketinin değerinin büyük ölçüde iki 
önemli unsura; firmanın sahip olduğu entelektüel sermayenin miktarı ve firmanın bu entelektüel sermayeyi piyasada kaldıraç etkisi yaratmak amacıyla kullanabilme yeteneğine, yönelik piyasa beklentileri ve inançları çerçevesinde şekillendiği düşünülmektedir. Kaldıraç faktörü, firmanın işletme ve pazarlama stratejileri arasından ticarileştirilebilecek olan yenilikleri seçme ve bunları nakde dönüştürme gücü olduğunu ifade etmektedir (Ankara Sanayi Odası, 2003).

Bir bilgi firmasının değeri, o firmanın maddi varlıklarının değeri ile entelektüel sermayesi tarafından yaratılan nakit akışlarının indirgenmiş değerinin toplamına eşit olmaktadır. Entelektüel sermayeye dayalı işletmelerde entelektüel sermaye, nakit akışları yaratmada kullanılan yenilikleri oluşturmakta ve onları nakde dönüştürerek nakit akışlarının kaynağı olmaktadır (Ankara Sanayi Odası, 2003).

\section{6. ÇIMENTO SEKTÖRÜ HAKKINDA GENEL BILGi}

Türk çimento sektörü, 1911 yılında 20.000 ton/yıl kapasiteli bir fırınla Darıca'da üretime başlamıştır. Daha sonra bu fabrika 1923 yılında tevsi edilerek kapasitesi 40.000 ton/yıl'a yükseltilmiştir. 1950 'den sonra Türkiye Çimento Sanayisi T.A.Ş.'nin (ÇiSAN) kurulmasıyla üretim artışı sağlanmasına rağmen 1970'lere dek talebin yeterli derecede karşılanamaması nedeniyle çimento ithalatı devam etmiştir.

Sektör, Türkiye'de yıldan yıla artan ihracat hacmi ile GSMH'da önemli bir yer sahibi olmanın yanında, sağladığı önemli istihdam düzeyiyle de ekonomik yapı içindeki önemini korumaktadır. Makroekonomik dalgalanmaların ve istikrarsızlıkların ilk etkisini gösterdiği sektörlerden biri olan çimento sektörü, yaşanan ekonomik krizlerden olumsuz yönde etkilenmekte olup, inşaat sektörünün ana girdilerinden birini sağlaması sebebiyle, bu sektördeki dalgalanmalardan doğrudan etkilenmektedir. Günümüzde sektör, hammadde konusunda tamamen kendi kaynaklarını kullanmakta olup, üretimiyle ülke ihtiyacını karşılayabilmektedir. İthalattaki payı az olan çimento sektörü, ihracattaki payını her geçen gün arttırmakta ve dünyanın 90 ülkesine satış yapmaktadır. İhracatın büyük bölümü Rusya, Irak, Suriye ve İtalya'ya yapılmaktadır. Mevcut durumda, yurtiçi talebi karşılamakta sıkıntı çekmeyen, bunun yanı sıra ihracatını yaklaşık yüzde 150 oranlarında artıran sektör Avrupa'nın en büyük çimento ihracatçısı konumuna gelmiştir.

Çimento sektörü, inşaat sanayinin kayıt dışı olmayan en önemli kollarından biridir. Çimento sanayisinde talep, ülkenin ekonomik koşullarına ve yatırım ortamlarına bağı olarak değişmekte ve harcama yapılmayan dönemlerde durgun bir seyir izlemektedir (T.C. Bilim, Sanayi ve Teknoloji Bakanlığı. 2013).

Tablo 1: Türk Çimento Sektörü Üretim ve Tüketim Miktarları

\begin{tabular}{|c|c|c|}
\hline Yıllar & Üretim (milyon ton) & Tüketim (milyon ton) \\
\hline 2000 & 35,95 & 31,51 \\
\hline 2001 & 29,96 & 25,08 \\
\hline 2002 & 32,76 & 26,81 \\
\hline 2003 & 35,10 & 28,11 \\
\hline 2004 & 38,80 & 30,67 \\
\hline 2005 & 42,79 & 35,08 \\
\hline 2006 & 47,40 & 41,61 \\
\hline
\end{tabular}




\begin{tabular}{|l|l|l|}
\hline 2007 & 49,26 & 42,46 \\
\hline 2008 & 51,43 & 40,57 \\
\hline 2009 & 58,00 & 39,96 \\
\hline 2010 & 62,70 & 62,53 \\
\hline 2011 & 63,40 & 62,90 \\
\hline 2012 & 60,30 & 62,30 \\
\hline
\end{tabular}

Kaynak: Sanayi Genel Müdürlüğü Sektörel Raporlar ve Analizler: Çimento Sektörü Raporu, 2013

Çimento sektöründe 2011 yılı kapasite kullanım oranı verilerine göre çimento kapasite kullanım oranı bölgeler bazında ortalama \% 63,41 olarak gerçekleşmiştir.

\section{Tablo 2: Çimento Sektörü 2011 Yılı Kapasite Miktarları}

\begin{tabular}{|l|c|c|}
\hline TON & Klinker Kapasitesi & Çimento Kapasitesi \\
\hline Marmara & 17.481 .907 & 27.404 .660 \\
\hline Ege & 5.997 .123 & 8.491 .200 \\
\hline Akdeniz & 15.869 .750 & 25.708 .645 \\
\hline Karadeniz & 5.951 .080 & 11.697 .210 \\
\hline İç Anadolu & 9.714 .773 & 15.490 .300 \\
\hline Doğu Anadolu & 3.977 .000 & 7.386 .640 \\
\hline G.Doğu Anadolu & 6.137 .000 & 10.306 .503 \\
\hline
\end{tabular}

Kaynak: Sanayi Genel Müdürlüğü Sektörel Raporlar ve Analizler: Çimento Sektörü Raporu, 2013

Tabloda görüldüğü gibi çimento kapasitesi en yüksek olan bölge Marmara Bölgesi'dir, bu nedenle çalışmamızda yer alan firmaların tümü Marmara Bölgesi'nden seçilmiştir.

\section{ARAŞTIRMANIN METODOLOJISi}

Çalışmamızda Marmara Bölgesi'nde faaliyet gösteren, halka açık 5 çimento fabrikasının 2010-2013 yılları arasındaki Entelektüel Sermayeleri, hesaplanmış maddi olmayan değer yöntemini kullanılarak belirlenmiştir. Araştırma kapsamına alınan şirketler; Bolu Çimento A.Ş., Bursa Çimento A.Ş., Nuh Çimento A.Ş., Aslan Çimento A.Ş. ve Çimsa Çimento A.Ş.'dir. İlgili firmaların 2011-2012-2013 yıllarına ait bilançoları kullanılarak hesaplamalar yapılmıştır. Firmaların gerek vergi yüklerine gerekse ortalama ağırlıklı sermaye maliyetlerinin belirlenmesine yönelik olarak veri temininin mümkün olmayışı nedeniyle ön kabullerde bulunulmuş ve araştırma kapsamındaki tüm firmalara genellemek zorunda kalınmıştır. Bunlar çalışmanın kısıtlarıdır. Söz konusu kısıtların araştırmanın bir eğilim belirleme niteliğine şüphe düşürmemesi dileğiyle, çalışmada yer alan sonuçlar sonraki çalışmaların dikkatine sunulmaktadır.

\section{BULGULAR}

Araştırmanın bulguları aşağıdaki bölümde yer almaktadır. Hesaplamalarda küsuratlar dikkate alınmamıştır. Para birimi TL olarak verilmiştir.

Araştırma kapsamındaki firmaların 2011-2012-2013 yıllarına ilişkin dönem karı ve söz konusu yıllara ilişkin olarak hesaplanan ortalama kazanç tutarları TL olarak Tablo 1'de gösterilmektedir. 
Tablo 3: Araştırma Kapsamındaki Firmaların Dönem Karları (TL)

\begin{tabular}{|c|c|c|c|c|}
\hline Firmalar & $\mathbf{2 0 1 3 - 2 0 1 2}$ & $\mathbf{2 0 1 2 - 2 0 1 1}$ & $\mathbf{2 0 1 1 - 2 0 1 0}$ & Ortalama Dönem Karı \\
\hline Aslan Çimento & 32.816 .316 & 37.432 .279 & 13.380 .084 & 27.876 .226 \\
\hline Bolu Çimento & 44.640 .287 & 24.639 .084 & 20.063 .406 & 29.780 .925 \\
\hline Bursa Çimento & 36.859 .875 & 16.389 .280 & 55.590 .605 & 36.279 .920 \\
\hline Çimsa Çimento & 302.280 .410 & 111.272 .702 & 123.395 .490 & 178.982 .867 \\
\hline Nuh Çimento & 87.912 .481 & 64.282 .668 & 75.376 .712 & 75.857 .287 \\
\hline
\end{tabular}

Tablo 3'den çıkarılabilecek sonuca göre en yüksek karlılığa sahip şirket, 178.982.867.-TL ile Çimsa Çimento Şirketidir. Ikinci sırada 75.857.287.- TL ile Nuh çimento gelmektedir, üçüncü sırada 36.279.920.-TL ile Bursa Çimento şirketi yer almaktadır, dördüncü sırada 29.780.925.-TL ortalama dönem karı ile Bolu çimento, beşinci sırada 27.876.226.-TL ile Aslan Çimento bulunmaktadır.

Araştırma kapsamındaki firmaların 2011-2012-2013 yıllarına ilişkin olarak sahip oldukları maddi duran varlık tutarlarına ilişkin veriler Tablo 4 'de sunulmaktadır.

Tablo 4: Araştırma Kapsamındaki Şirketlerin Maddi Varlık Tutarları

\begin{tabular}{|l|c|c|c|c|}
\hline \multicolumn{1}{|c|}{ Firmalar } & $\mathbf{2 0 1 3 - 2 0 1 2}$ & $\mathbf{2 0 1 2 - 2 0 1 1}$ & $\mathbf{2 0 1 1 - 2 0 1 0}$ & Ortalama Maddi Varlık Tutarları \\
\hline Aslan Çimento & 171.800 .203 & 157.447 .846 & 151.709 .975 & 160.319 .341 \\
\hline Bolu Çimento & 138.658 .585 & 116.480 .209 & 111.519 .076 & 122.219 .290 \\
\hline Bursa Çimento & 136.717 .541 & 126.353 .474 & 146.859 .641 & 136.643 .552 \\
\hline Çimsa Çimento & 716.115 .307 & 685.345 .670 & 564.540 .633 & 655.333 .870 \\
\hline Nuh Çimento & 134.251 .827 & 79.825 .804 & 563.042 .252 & 259.039 .962 \\
\hline
\end{tabular}

Tablo 4'den çıkarılabilecek sonuca göre araştırma kapsamındaki firmalar arasında sahip olunan maddi duran varlıklar toplamı bakımından farklıııklar vardır. En yüksek maddi duran varlık değeri Çimsa Çimento Şirketi'ne aittir. İkinci sırada Nuh Çimento, üçüncü sırada Bursa Çimento şirketi yer almaktadır, dördüncü sırada Aslan çimento, beşinci sırada Bolu Çimento bulunmaktadır. Tablo 3 ve Tablo 4 'den elde edilen verilere bakıldığında genel olarak ortalama maddi duran varlık değerleri ile dönem karları arasında doğru orantı olduğu söylenebilir. Bu durumun tek istisnası olan Bolu Çimento şirketi için karlılık oranı (Tablo 3) Aslan Çimento şirketinden fazla olduğu halde, ortalama maddi varlık tutarları (Tablo 4) bakımından sıralamada Aslan Çimento şirketinin gerisinde kalmıştır

Araştırma kapsamındaki firmalarda sahip olunan ortalama maddi varlıkların ortalama karlılık oranlarına ilişkin bulguları Tablo 5' de sunulmaktadır.

Tablo 5: Ortalama Maddi Varlık Kazanç Oranları (TL)

\begin{tabular}{|l|c|c|c|}
\hline Firmalar & $\begin{array}{c}\text { Ortalama Dönem Karı } \\
\mathbf{( 1 )}\end{array}$ & $\begin{array}{c}\text { Ortalama Maddi Varlık Tutarı } \\
\mathbf{( 2 )}\end{array}$ & $\begin{array}{c}\text { Ortalama Maddi Varlık Kazanç } \\
\text { Oranı (1/2) }\end{array}$ \\
\hline Aslan Çimento & 27.876 .226 & 160.319 .341 & $\% 1.7$ \\
\hline Bolu Çimento & 29.780 .925 & 122.219 .290 & $\% 2.4$ \\
\hline Bursa Çimento & 36.279 .920 & 136.643 .552 & $\% 2.6$ \\
\hline Çimsa Çimento & 178.982 .867 & 655.333 .870 & $\% 2.7$ \\
\hline Nuh Çimento & 75.857 .287 & 259.039 .962 & $\% 2.9$ \\
\hline
\end{tabular}


Tablo 5'e göre maddi varlık karlıık oranının en yüksek olduğu firma Nuh Çimento A.Ş'dir, Bu firmayı sırasıyla Çimsa Çimento, Bursa Çimento, Bolu Çimento, Aslan Çimento takip etmektedir. Tablo 4 ve Tablo 5'den elde edilen verilere bakıldığında, yatırım büyüklüğü ile yatııımın karlıı̆̆ı oranlarının Çimsa Çimento şirketi ve Nuh Çimento şirketinde yüksek olmasına rağmen yatırım büyüklüğü bakımından üçüncü sırada yer alan Aslan Çimento A.Ş.'nin karlııık oranı en düşük çıkmıştır.

\section{Tablo 6: Sektörde Ortalama Maddi Varlık Kazanç Oranları (TL)}

\begin{tabular}{|l|c|c|}
\hline Firmalar & Dönem Karı & Maddi Varlık Tutarı (2) \\
\hline Adana Çimento & 77.760 .948 & 246.161 .955 \\
\hline Afyon Çimento & $(3.495 .617)$ & 26.272 .756 \\
\hline Aslan Çimento & 27.876 .226 & 160.319 .341 \\
\hline Batıçim Batı Anadolu Çimento & 31.139 .766 & 362.176 .302 \\
\hline Batısöke Çimento & 5.534 .367 & 125.176 .376 \\
\hline Baştaş Başkent Çimento & 27.792 .504 & 229.632 .454 \\
\hline Bolu Çimento & 29.780 .925 & 122.219 .290 \\
\hline Bursa Çimento & 36.429 .920 & 136.643 .552 \\
\hline Çimentaş İzmir Çimento & 31.550 & 537.387 \\
\hline Çimsa Çimento & 178.982 .86 & 655.333 .870 \\
\hline Göltaş Çimento & 18.125 .54 & 286.418 .350 \\
\hline Konya Çimento & 34.155 .496 & 176.993 .432 \\
\hline Mardin Çimento & 57.975 .000 & 110.726 .876 \\
\hline Nuh Çimento & 75.857 .287 & 259.039 .961 \\
\hline Ünye Çimento & 55.477 .726 & 129.562 .683 \\
\hline TOPLAM & $\mathbf{6 5 3 . 4 2 4 . 5 1 4 -}$ & $\mathbf{3 . 0 2 7 . 2 1 4 . 5 8 9}$ \\
\hline \multicolumn{2}{|c|}{ (A) } & (B) \\
\hline
\end{tabular}

Sektördeki toplam yatırım büyüklüğü 3.027.214.589.-TL'dir. Söz konusu yatırımlardan elde edilen dönem kazançlarının ortalaması 653.424.514.-TL'dir. Sektörde maddi varlık karlıık oranı \% 2.1 olarak hesaplanmıştır.

Marmara Bölgesinde faaliyet gösteren çimento işletmelerinin Ortalama Maddi Varlık Karlııık Oranı aşağıdaki Tablo 7'de hesaplanmıştır.

Tablo 7: Marmara Bölgesinin Ortalama Maddi Varlık Karlılık Oranı

\begin{tabular}{|l|c|}
\hline \multicolumn{1}{|c|}{ Firmalar } & Ortalama Maddi Varık Kazanç Oranı \\
\hline Aslan Çimento & $\% 1.7$ \\
\hline Bolu Çimento & $\% 2.4$ \\
\hline Bursa Çimento & $\% 2.6$ \\
\hline Çimsa Çimento & $\% 2.7$ \\
\hline Nuh Çimento & $\% 2.9$ \\
\hline Marmara Bölgesi Sektör Ortalaması & \%2.4 \\
\hline
\end{tabular}

Tablo 6'ye göre tüm sektörün ortalamasının 2.1, Tablo 7'ye göre ise Marmara Bölgesinin sektör ortalaması \% 2.4 olarak hesaplanmıştır. Bundan sonraki bölümdeki hesaplamalarda daha güvenilir sonuçlar elde edebilmek için sektör ortalaması yerine Marmara Bölgesinin sektör ortalaması olan \%2.4 kullanılacaktır. 
Firmanın maddi varlıklarından sektör ortalamasının üzerinde elde ettiği kazançlar "ek kazanç" olarak tanımlanır. Firma maddi varlıklarının ortalama tutarı ile sektördeki ortalama maddi varlık karlıık oranının çarpılmasından elde edilen tutar normal kazanç olarak tanımlanmıştır. Ek kazanç, firmanın ortalama dönem karı tutarından normal kazanç tutarının çıkarılması suretiyle bulunmuştur.

Tablo 8: Araştırma Kapsamındaki Şirketlerin Ek Kazanç Tutarları(TL)

\begin{tabular}{|l|c|c|c|r|r|}
\hline \multicolumn{1}{|c|}{ Firmalar } & $\begin{array}{c}\text { Ortalama } \\
\text { Maddi Varlık } \\
\text { Tutarı (1) }\end{array}$ & $\begin{array}{c}\text { Sektördeki Ort. } \\
\text { Maddi } \\
\text { Var.Karlılığ (2) }\end{array}$ & $\begin{array}{c}\text { Normal } \\
\text { Kazanç } \\
\text { (1X2) }\end{array}$ & $\begin{array}{c}\text { Ortalama } \\
\text { Dönem Karı }\end{array}$ & $\begin{array}{c}\text { (4) } \\
\text { Ek Kazanç } \\
\text { (4-3) }\end{array}$ \\
\hline Aslan Çimento & 160.319 .341 & $\% 2.4$ & 3.847 .664 & 27.876 .226 & \\
\hline Bolu Çimento & 122.219 .290 & $\% 2.4$ & 2.933 .263 & 29.780 .925 & 26.847 .662 \\
\hline Bursa Çimento & 136.643 .552 & $\% 2.4$ & 3.279 .445 & 36.279 .920 & 33.000 .475 \\
\hline Çimsa Çimento & 655.333 .870 & $\% 2.4$ & 15.728 .012 & 178.982 .867 & 163.254 .854 \\
\hline Nuh Çimento & 259.039 .962 & $\% 2.4$ & 6.216 .959 & 75.857 .287 & 69.640 .328 \\
\hline
\end{tabular}

Tablo 8'in sonucuna göre en yüksek ek kazanç Çimsa Çimento'ya aittir. Bu firmayı sırasıyla Nuh Çimento, Bursa Çimento, Bolu Çimento izlemektedir. Aslan Çimento Firmasının ortalama maddi varlık karlılığı oranı, sektör ortalamasının altında kaldığı için ek kazanç hesaplanmamıştır. İşletmenin getiri oranı sektör ortalamasının altında ise hesaplanmış maddi olmayan değer yöntemi uygulanamaz. Aslan Çimento firması entelektüel sermaye hesaplamalarına katılmayacaktır.

Firmanın entelektüel sermayesinin değeri ek kazanç tutarından bu kazanca ilişkin vergi çıkarıldıktan sonra bulunan tutarın, firmanın ortalama ağırlıklı sermaye maliyetine bölünmesi suretiyle hesaplanır (Uzay ve Savaş, 2003: 175). Tablo 9'da her bir firmaya ilişkin entelektüel sermaye değeri hesaplanmıştır. Bu hesaplama yapılırken başta bahsedilen veri olmayışı nedeni ile, ağılıklı sermaye maliyeti olarak TC Merkez Bankası Avans işlemlerinde kullanılan faiz oranları baz alınmıştır. 2010 yılı ve 2013 yılı avans faiz oranlarının ortalaması alınarak Ortalama Ağırlıklı Sermaye Maliyeti yerine kullanılmıştır. İlgili dönem faiz oranları; 2010 yılı 0,15, 2011 yılı 0,1775, 2012 yılı 0,165, 2013 yılı ilk altı ay 0,11 ikinci altı ay 0,1175 . Ilgili yılların ortalama faiz oranı ise; 0,135625 olarak hesaplanmıştır. Çalışmada bu değer yaklaşık \%14 olarak alınmıştır.

Tablo 9: Araştırma Kapsamındaki Firmalarda Entelektüel Sermaye Tutarları (TL)

\begin{tabular}{|c|c|c|c|c|c|}
\hline Firmalar & $\begin{array}{c}\text { Brüt Ek } \\
\text { Kazanç(1) }\end{array}$ & $\begin{array}{c}\text { Ek Kazancın } \\
\text { Vergisi(2) }\end{array}$ & $\begin{array}{c}\text { Net Ek Kazanç } \\
\text { (1-2) (3) }\end{array}$ & $\begin{array}{c}\text { Ort. Ağır. } \\
\text { Sermaye } \\
\text { Maliyeti }\end{array}$ & $\begin{array}{c}\text { Entelektüel } \\
\text { Sermaye Tutarı } \\
(3 / 4)(5)\end{array}$ \\
\hline Bolu Çimento & 26.847 .662 & 5.369 .532 & 21.478 .130 & $\% 14$ & 153.415 .212 \\
\hline Bursa Çimento & 33.000 .475 & 6.600 .095 & 26.400 .380 & $\% 14$ & 188.574 .141 \\
\hline Çimsa Çimento & 163.254 .854 & 32.650 .971 & 130.603 .883 & $\% 14$ & 932.884 .881 \\
\hline Nuh Çimento & 69.640 .328 & 13.928 .066 & 55.712 .262 & $\% 14$ & 397.944 .731 \\
\hline
\end{tabular}

Tablo 8'de hesaplanmış olan ek kazanç tutarları, Tablo 9' da brüt kazanç olarak tanımlanmış ve brüt kazanç üzerinden vergi hesaplanmıştır. Bütün firmalar için \%20 kurumlar vergisi oranı uygulanmıştır. Ortalama ağırlıklı sermaye maliyeti ise \% 14 olarak kabul edilmiştir. 
Tablo 9'ya göre tutar olarak entelektüel sermayenin en yüksek olduğu firma Çimsa Çimento, bu firmayı sırasıyla Nuh Çimento, Bursa Çimento, Bolu Çimento takip etmektedir.

Çalışmanın bu kısmında tutar olarak hesaplanan entelektüel sermaye değerlerini daha anlamlı hale getirmek için hesaplanan entelektüel sermaye değerleri ile söz konusu firmaların bazı finansal göstergeleri arasındaki ilişkiler oran yöntemi ile analiz edilecektir. Bu amaçla firmaların ortalama defter değeri Tablo 10' da hesaplanmıştır.

Tablo 10: Firmaların Defter Değeri(TL)

\begin{tabular}{|l|r|r|r|r|r|r|}
\hline \multirow{2}{*}{ Firmalar } & \multicolumn{3}{|c|}{ Dış Borç Toplamı } & \multicolumn{1}{l|}{$\begin{array}{l}\text { Ortalama } \\
\text { Borç Tutarı }\end{array}$} & $\begin{array}{l}\text { Ort. Net Aktif } \\
\text { Tutarı }\end{array}$ & Defter Değeri \\
\cline { 2 - 7 } & 2011 & 2012 & 2013 & & & \\
\hline Çimsa Çimento & 388.947 .128 & 536.151 .679 & 313.489 .660 & 412.862 .822 & 1.420 .155 .589 & 1.007 .292 .767 \\
\hline Nuh Çimento & 389.344 .931 & 499.994 .081 & 466.872 .966 & 452.070 .659 & 1.312 .085 .594 & 860.014 .935 \\
\hline Bursa Çimento & 113.000 .777 & 136.301 .451 & 162.924 .193 & 137.408 .807 & 463.554 .372 & 326.145 .565 \\
\hline Bolu Çimento & 33.805 .555 & 36.342 .900 & 61.034 .589 & 43.727 .681 & 256.576 .799 & 212.849 .118 \\
\hline
\end{tabular}

Defter değeri, firmanın net aktif toplamından tüm borçları çıkarıldıktan sonra kalan pozitif farktır. Tablo 10' da analiz dönemine ilişkin borç tutarları belirlenmiş ve ortalama net aktif tutarından çıkarılmak suretiyle her bir firmaya ait defter değerleri bulunmuştur. Tablo 10'a göre en yüksek defter değeri Çimsa Çimento firmasına aittir. İkinci sırada Nuh Çimento gelmektedir. Bursa Çimento üçüncü, Bolu Çimento dördüncü sıradadır.

Ortalama defter değerleri ve ortalama net aktif toplamları ile döneme ilişkin entelektüel sermaye tutarları arasındaki oransal ilişkiler Tablo 11'de sunulmuştur.

Tablo 11: Entelektüel Sermaye, Defter Değeri ve Ortalama Net Aktif Toplamı ilişkileri

\begin{tabular}{|l|c|c|c|c|c|}
\hline Firmalar & $\begin{array}{c}\text { Entelektüel Sermaye } \\
\text { Tutarı }\end{array}$ & Defter Değeri & $\begin{array}{c}\text { Ortalama Net Aktif } \\
\text { Tutarı }\end{array}$ & $\begin{array}{c}\text { Entelektüel Sermaye/ } \\
\text { Defter Değeri }\end{array}$ & $\begin{array}{c}\text { Entelektüel } \\
\text { Sermaye/Net } \\
\text { Aktif Oranı }\end{array}$ \\
\hline Çimsa Çimento & 932.884 .881 & 1.007 .292 .767 & 1.420 .155 .589 & $\% 93$ & $\% 66$ \\
\hline Bolu Çimento & 153.415 .212 & 212.849 .118 & 256.576 .799 & $\% 72$ & $\% 60$ \\
\hline Bursa Çimento & 188.574 .141 & 326.145 .565 & 463.554 .372 & $\% 58$ & $\% 41$ \\
\hline Nuh Çimento & 397.944 .731 & 860.014 .935 & 1.312 .085 .594 & $\% 46$ & $\% 30$ \\
\hline
\end{tabular}

Tablo 11 'de araştırma kapsamındaki firmaların ortalama defter değerleri ve ortalama net aktif tutarları ile döneme ilişkin entelektüel sermaye tutarları arasındaki oransal ilişkileri göstermektedir. Araştırma kapsamındaki firmalar entelektüel sermaye/ defter değeri oranı bakımından en yüksekten düşüğe Çimsa Çimento, Bolu Çimento, Bursa Çimento ve Nuh Çimento şeklinde sıralanmaktadır, entelektüel sermaye/ net aktif oranı hesaplanmasında da sıralama aynıdır.

Firmaların piyasa verileri ve elde edilen sonuçlarda karşılaştırılabilir. Elde edilen verilere göre firmaların piyasa verilerine ilişkin bulgular Tablo 12'de verilmiştir.

Tablo 12: İşletmelerin Entelektüel Sermaye ve Piyasa Performansı Karşılaştırması

\begin{tabular}{|l|c|c|c|c|c|}
\hline Firmalar & $\begin{array}{c}\mathbf{2 0 1 3} \text { Yılı Kapanış } \\
\text { Piyasa Değeri }\end{array}$ & $\begin{array}{c}\text { Fiyat Kazanç } \\
\text { Oranı (\%) }\end{array}$ & $\begin{array}{c}\text { Piyasa Değeri Defter } \\
\text { Değeri Oranı (\%) }\end{array}$ & $\begin{array}{c}\text { Öz Sermaye } \\
\text { Karlılık Oranı (\%) }\end{array}$ & $\begin{array}{c}\text { Entelektüel Sermaye/ } \\
\text { Defter Değeri (\%) }\end{array}$ \\
\hline Aslan Çimento & 27,42 & 98,3 & 9,61 & 0,134 & -- \\
\hline Çimsa Çimento & 9,52 & 5,7 & 1,56 & 0,292 & 0,93 \\
\hline Bolu Çimento & 2,47 & 7,8 & 1,49 & 0,204 & 0,72 \\
\hline Bursa Çimento & 3,85 & 21 & 1,73 & 0,12 & 0,58 \\
\hline Nuh Çimento & 8,27 & 15,2 & 1,84 & 0,101 & 0,46 \\
\hline
\end{tabular}


Tablo 10, Tablo 11 ve Tablo 12 birlikte değerlendirildiğinde işletmelerin entelektüel sermaye birikimlerini genel olarak piyasaya yansıtabildikleri, sadece Aslan Çimentonun beklenenden daha iyi bir performans gösterdiği görülmektedir. Aslan Çimentonun getiri oranı sektör ortalamasının altında olmasına rağmen piyasa performansı diğer firmalara göre daha önde görünmektedir. Bunun dışındaki durumlarda ise firmalar entelektüel sermaye birikimlerini piyasaya yansıtabilmiş sayılabilirler.

\section{SONUÇ}

Bilgi ekonomisi olarak yeni bir ekonomik yapının meydana gelmesi işletmeler açısından maddi olmayan varlıkların değerini arttırmış, işletmelerin defter değeri ile piyasa değeri arasında büyük farklar ortaya çıkmaya başlamıştır. Entelektüel sermaye ismini alan bu fark işletmelerin ölçmek ve yönetmek zorunda oldukları bir durum ortaya çıkarmıştır. Bu çalışmada Marmara Bölgesinde faaliyet gösteren ve hisseleri BiST' te işlem gören 5 çimento firmasının 2011-2012-2013 dönemine ilişkin entelektüel sermayeleri hesaplanmış ve defter değerleri ile net aktif tutarları arasındaki oransal iliş̧kiler belirlenmiştir. Hesaplamalarda "Hesaplanmış Maddi Olmayan Değer Yöntemi” kullanılmıştır. Çalışma sonuçlarının özeti aşağıda yer almaktadır:

Bolu Çimento'nun 153.415.212.-TL olan entelektüel sermayesi ortalama defter değerinin \% 72'sini, ortalama net aktif tutarının da \% 60'ını oluşturmaktadır.

Bursa Çimento'nun 188.574.141.-TL olan entelektüel sermayesi ortalama defter değerinin $\% 58$ 'ini, ortalama net aktif tutarının da \% 41'ini oluşturmaktadır.

Çimsa Çimento'nun 932.884.881.-TL olan entelektüel sermayesi ortalama defter değerinin \% 93'ünü, ortalama net aktif tutarının da \% 62'sini oluşturmaktadır.

Nuh Çimento'nun 397.944.731.-TL olan entelektüel sermayesi ortalama defter değerinin \% 46 'sını, ortalama net aktif tutarının da \% 30' unu oluşturmaktadır.

Firmalar genel olarak entelektüel sermaye birikimlerini piyasa performanslarına da yansıtmışlardır.

$\mathrm{Bu}$ sonuçlara göre farklı sektörlerdeki benzer çalışmalar incelendiğinde, araştırma kapsamındaki firmaların entelektüel sermaye açısından güçlü oldukları ortaya çıkmıştır. Günümüz artık bilgiye dayalı bir ekonomi haline gelmiştir ve bilgiye dayalı ekonomilerde rekabet gücünü korumak isteyen firmalar entelektüel sermayeye gereken önemi vermek durumundadır. Çalışmada incelenen firmaların bu önemi kavrayabildiği görülmektedir. Bu durum firma değeri açısından da önem arz etmektedir. Entellektüel sermaye oranlarının tüm firmalar için \% 50 'yi geçmiş olması aynı zamanda net aktif oranı içindeki payında yüksek olması firma değerlerinin yükselmesi açısından fark yaratmaktadır. 


\section{KAYNAKÇA}

Alagöz, A., Özpeynirci, R. (2007), "Bilgi Toplumunda Entelektüel Varlıklar ve Raporlanması", Afyon Kocatepe Üniversitesi i.i..B.F.Dergisi, Cilt:9, Sayı:11, ss:167-184.

Ankara Sanayi Odası. (2013), “Entelektüel Sermayenin Firma Değeri Üzerine Etkisi”, Kaynak: http://www.aso.org.tr /kurumsal/media/kaynak /TUR/asomedya/nisan 2003/dosyanisan2003.html, (Erişim Tarihi: 28.04.2014).

Arıkboğa, Ş., (2003), “Entelektüel Sermaye”, İstanbul: Derin Yayınları.

Bontis, N. and others. (2000), "Intellectual Capıtal And Business Performance İn Malaysian İndusstries", Journal of Intellectual Capital, Vol.1, No.1, ss:85-100.

Çelik, A. E., Perçin, S. (2000), "Entelektüel Sermayenin İşletme Bazında Ölçülmesi ve Değerlendirilmesi”, Muhasebe ve Denetime Bakış Dergisi, Yıl: 1, Sayı: 2, ss. 111-118.

Çıkrıkçı, M., Daştan, A., (2002), “Entelektüel Sermayenin Temel Finansal Tablolar Aracılığıyla Sunulması”, Bankacılar Dergisi, Sayı: 43, ss. 18-32.

Ercan, M: K. ve diğerleri,. (2003), Değere Dayalı Yönetim ve Entellektüel Sermaye, Ankara: Gazi Kitabevi.

Kamu Aydınlatma Platformu., İlgili Firmaların 2011-2012-2013 yıllarına ait Bilanço ve Gelir Tabloları Kaynak: www.kap.gov.tr, (Erişim Tarihi: 28.04.2014).

Karacan, S., (2004), “Entelektüel Sermaye ve Yönetimi”, Mali Çözüm Dergisi, Sayı: 69, ss:177-199.

Görmüş, A. Ş., (2009), "Entelektüel Sermaye ve İnsan Kaynakları Yönetiminin Artan Önemi”, Afyon Kocatepe Üniversitesi İ.̇.B.F. Dergisi, Cilt:11, Sayı:1, ss:57-75.

İpçioğlu, i., (2007), “Kobilerde Entelektüel Sermayenin İşletme Performansına Etkisi”, Süleyman Demirel Üniversitesi i.i.̇.F. Dergisi, Cilt:12, Sayı:3, ss:133-146.

Önce, S., (1999), "Muhasebe Bakış Açısı ile Entelektüel Sermaye”, İktisadi ve İdari Bilimler Fakültesi Yayınları, No:151, Eskişehir.: Anadolu Üniversitesi Yayını.

Özçetin, N., (2010), Maddi Olmayan Varlıkların Raporlanması Ve Halka Açık Şirketlerde Maddi Olmayan Varlıkların Raporlanmasına Yönelik Bir Araştırma, Yozgat: Bozok Üniversitesi Sosyal Bilimler Enstitüsü, Yüksek Lisans Tezi.

Şamiloğlu, F., (2002), Entelektüel Sermaye, Ankara: Gazi Kitabevi.

Şişman, B., Şişman, F. A., (2004), “Entelektüel Sermayenin Unsurları, Ölçülmesi ve Muhasebeleştirilmesi”, Yaklaşım Dergisi, Nisan, Sayı:136.

T.C.Bilim, Sanayi ve Teknoloji Bakanlığı. (2013), "Sanayi Genel Müdürlüğü Sektörel Raporlar ve Analizler: Çimento Sektörü Raporu (2013/1)", Kaynak: http:// www.sanayi.gov.tr/Files/Documents/cimento-sektor-raporu-20116042013164544.pdf, (Erişim Tarihi: 16.05.2014).

Uzay, Ş., Savaş, O., (2003), “Entelektüel Sermayenin Ölçülmesi: Mobilya Sektöründe Karşılaştırmalı Bir Uygulama Örneği, Erciyes Üniversitesi İktisadi ve İdari Bilimler Fakültesi Dergisi, Sayı: 20, ss. 163-181.

Yalama, A., (2006), “Entelektüel Sermayenin Entelektüel Katma Değer Katsayısı (VAIC) İle Ölçülmesi Ve Veri Zarflama Analizi (DEA) Yöntemi Kullanılarak Karlılığa Etkisinin Sınanması: IMKB'ye Kote Bankalarda Uygulaması”, iktisadi Araştırmalar Vakfı, İstanbul.

Zor, İ., Cengiz, S., (2013), “Entelektüel Sermaye ile Firma Değeri Arasındaki i̇lişki: Borsa İstanbul'da Bir Araştırma”, Çankırı Karatekin Üniversitesi İktisadi ve İdari Bilimler Fakültesi Dergisi, Sayı: 2013-1, ss. 37-56. 